\title{
BIO-OXIDAÇÃO DE CONCENTRADO REFRATÁRIO DE OURO POR SULFOBACILLUS THERMOSUFIDOOXIDANS COM FOCO NO COMPORTAMENTO DO ANTIMÔNIO
}

\author{
Suzimara Reis Silva' \\ Liliane Coelho de Carvalho ' \\ Flávio Luiz Martins ' \\ Romeu Marra Giardini ' \\ Versiane Albis Leão ${ }^{1 *}$
}

\section{Resumo}

Foi investigada a bio-oxidação de um concentrado sulfetado de ouro contendo pirita, estibinita, gudmundita e arsenopirita por Sulfobacillus thermosulfidooxidans (DSMZ 9293). Foram avaliados os efeitos da concentração inicial de íons $\mathrm{Fe}^{2+}\left(0 \mathrm{~g} \mathrm{~L}^{-1}-10,0 \mathrm{~g} \mathrm{~L}^{-1}\right)$ e do $\mathrm{pH}$ da suspensão $(\mathrm{I}, 50, \mathrm{I}, 75$ e 2,00) na eficiência de bio-oxidação do concentrado, através do acompanhamento da extração de arsênio e da análise dos produtos de bio-oxidação. Os ensaios foram realizados em mesa agitadora termostatizada, a uma temperatura de $47^{\circ} \mathrm{C}$ e sob agitação de $150 \mathrm{~min}^{-1}$. Foi possível inferir que a suplementação com I0g/L de Fe efeito do $\mathrm{pH}$, a maior solubilização de arsênio foi constatada em $\mathrm{pH}$ I,75. As análises de DRX e MEV-EDS dos produtos de bio-oxidação confirmaram: (i) o efeito catalítico dos micro-organismos na oxidação da pirita e da arsenopirita; (ii) a baixa reatividade dos sulfetos de antimônio; (iii) a necessidade de suplementação de íons $\mathrm{Fe}^{2+}$ e (iv) melhores resultados de bio-oxidação em pH I,75 e 2,0 em relação ao pH I,5.

Palavras-chave: Bio-oxidação; S.thermossulfidooxidans, sulfeto, arsênio, antimônio.

\section{BIO-OXIDATION OF A REFRACTORY GOLD CONCENTRATE BY SULFOBACILLUS THERMOSUFIDOOXIDANS FOCOSING IN THE BEHAVIOUR OF ANTIMONY}

\begin{abstract}
The bio-oxidation of a gold concentrate containing pyrite, stibnite and arsenopyrite by Sulfobacillus thermosulfidooxidans (DSMZ 9293) was investigated. The effects of the initial $\mathrm{Fe}^{2+}$ concentration $\left(0 \mathrm{~g} \mathrm{~L}^{-1}-10.0 \mathrm{~g} \mathrm{~L}^{-1}\right)$ and $\mathrm{pH}(1.50, \mathrm{I} .75$ and 2.00 ) in the biooxidation of the sulphide concentrate were assessed through both arsenic extractions and the analysis of bio-oxidation products. The bio-oxidation tests were performed at $47^{\circ} \mathrm{C}$ under stirring $\left(150 \mathrm{~min}^{-1}\right)$ in a temperature controlled shaker,. It was inferred that the presence of $10 \mathrm{~g} / \mathrm{L} \mathrm{Fe}^{2+}\left(\right.$ as FeSO ${ }_{4} \cdot 7 \mathrm{H}_{2} \mathrm{O}$ ) resulted in the most efficient sulphide oxidation. When the effect of $\mathrm{pH}$ was analyzed, the highest arsenic dissolution was observed at $\mathrm{pH}$ I.75. XRD and SEM-EDS analysis of bio-oxidation products confirmed: (i) the catalytic effect of micro-organisms on the oxidation of pyrite and arsenopyrite; (ii) the low reactivity of antimony sulphides, (iii) the necessity of ferrous iron supplementation and (iv) better oxidation results at $\mathrm{pH} \mathrm{I} .75$ and 2.0 as compared to $\mathrm{pH} \mathrm{I} .50$.
\end{abstract}

Key-words: Bio-oxidation; S.thermossulfidooxidans, sulphides, arsenic, antimony.

\section{INTRODUÇÃO}

Os sulfetos como a pirita $\left(\mathrm{FeS}_{2}\right)$ e a arsenopirita (FeAsS), são constituintes frequentes em minérios auríferos. Usualmente, o ín cianeto não tem acesso ao ouro nestes sulfetos (minério refratário), o que exige a realização de uma etapa de pré-tratamento, antes da cianetação. Dentre os pré-tratamentos de minérios refratários de ouro inclui-se

'Programa de Pós-graduação em Engenharia de Materiais, Departamento de Engenharia Metalúrgica e de Materiais, Universidade Federal de Ouro Preto - UFOP, Ouro Preto, MG, Brasil.

*Autor correspondente: versiane@ufop.edu.br

2176-I523 (C) 2020. Silva et al. Publicado pela ABM. Este é um artigo publicado em acesso aberto (Open Access) sob a licença Creative Commons Attribution, que permite uso, distribuição e reprodução em qualquer meio, sem restrições desde que o trabalho original seja corretamente citado. 
a bio-oxidação, a qual é caracterizada pelo emprego de micro-organismos capazes de oxidar os sulfetos minerais e, assim, expor o ouro retido na estrutura cristalina dos minerais ao agente lixiviante [I].

Várias espécies de micro-organismos com habilidade de oxidar $\mathrm{Fe}^{2+} \mathrm{e} /$ ou compostos sulfetados já foram identificadas [2]. Dentre eles, a espécie mesófila Acidithiobacillus ferrooxidans é a mais utilizada em estudos de oxidação bacteriana de sulfetos [3]. Entretanto, a fim de melhorar a cinética de dissolução em relação à apresentada nos sistemas contendo bactérias mesófilas, o uso de micro-organismos termófilos aparece como uma alternativa promissora [4].

Durante a bio-oxidação de sulfetos contendo ferro (p.ex. pirita e arsenopirita), ocorrem dois processos concomitantemente: (i) dissolução dos sulfetos, com consequente liberação de $\mathrm{Fe}$ e As e a formação de $\mathrm{SO}_{4}{ }^{2-}$ e (ii) precipitação de fases secundárias contendo tais constituintes [5-7]. A formação de jarosita contendo arsênio é comumente mencionada na literatura [5,6,8-I0], a qual é solução sólida substitucional de elementos constituintes da jarosita [9]. Em sistemas de biolixiviação/bio-oxidação, a formação de precipitados férricos é fortemente influenciada pelo $\mathrm{pH}$, temperatura e concentração de íons férricos, sendo que uma elevação na temperatura ou no valor do $\mathrm{pH}$ favorece a formação destes precipitados [5, I I].

Os micro-organismos envolvidos nos processos de bio-oxidação de sulfetos minerais podem sofrer efeitos deletérios na presença de elementos tóxicos em solução, tais como, arsênio, antimônio, cobre, zinco e prata [6]. Quanto ao antimônio (Sb), elemento pertencente ao grupo 15 da tabela periódica, é um semi-metal e, apesar do mesmo apresentar uma variedade de estados de oxidação $(-3 ; 0 ; 3 ; 5)$, ele é encontrado usualmente sob a forma pentavalente e trivalente em sistemas ambientais e biológicos [12]. A presença deste elemento em minérios submetidos à processos de bio-oxidação é verificada, principalmente, na forma de estibinita $\left(\mathrm{Sb}_{2} \mathrm{~S}_{3}\right)$ e gudmundita (FeSbS).

A capacidade de Acidithiobacillus ferrooxidans em oxidar estibinita é relatada na literatura [ 13,14$]$. Além disso, ambos estudos reportam que no decurso da bio-oxidação de estibinita, o íon $\mathrm{Sb}^{3+}$ é oxidado a $\mathrm{Sb}^{5+}$, levando a formação de óxidos e hidróxidos de antimónio, pouco solúveis $\left((\mathrm{SbO})_{2} \mathrm{SO}_{4}\right.$ e $\left.\left.\left(\mathrm{SbO}_{2}\right)_{2} \mathrm{SO}_{4}\right)\right)$, conforme descrito nas Equações I a 4 [13]:

$$
\begin{aligned}
& \mathrm{Sb}_{2} \mathrm{~S}_{3}+6 \mathrm{O}_{2} \stackrel{\text { At.ferooxidans }}{\rightarrow} \mathrm{Sb}_{2}\left(\mathrm{SO}_{4}\right)_{3} \\
& \mathrm{Sb}_{2}\left(\mathrm{SO}_{4}\right)_{3}+2 \mathrm{H}_{2} \mathrm{O} \leftrightarrow(\mathrm{SbO})_{2} \mathrm{SO}_{4}+2 \mathrm{H}_{2} \mathrm{SO}_{4} \\
& \mathrm{Sb}_{2}\left(\mathrm{SO}_{4}\right)_{3}+\mathrm{O}_{2}+\mathrm{H}_{2} \mathrm{SO}_{4} \leftrightarrow \mathrm{Sb}_{2}\left(\mathrm{SO}_{4}\right)_{5}+\mathrm{H}_{2} \mathrm{O} \\
& \mathrm{Sb}_{2}\left(\mathrm{SO}_{4}\right)_{5}+4 \mathrm{H}_{2} \mathrm{O} \leftrightarrow\left(\mathrm{SbO}_{2}\right)_{2} \mathrm{SO}_{4}+4 \mathrm{H}_{2} \mathrm{SO}_{4}
\end{aligned}
$$

Os trabalhos desenvolvidos por Torma e Gabra [13] e Luptákova et al. [14] não fazem menção sobre os possíveis efeitos deletérios do antimônio no processo de bio-oxidação.
Por outro lado, Tsaplina et al. [15] relataram o efeito prejudicial do elemento na bio-oxidação de concentrados de sulfetos auríferos. Além disso, os autores enfatizam os possíveis efeitos deletérios do $\mathrm{Sb}$ aos micro-organismos. Motivados por estes aspectos, eles investigaram o efeito da concentração de Sb ( $0,84 \%$ a $29,95 \%$ de sulfeto de antimônio; $0,47 \%$ a $2,5 \%$ de sulfeto de ferro e $0,01 \%$ a $0,4 \%$ de sulfeto de arsênio.) na bio-oxidação da amostra mineral, utilizando uma cultura mista de micro-organismos, composta por Sulfobacillus ssp, Leptospirillum ssp e Ferroplasma ssp. Foi constatado que os micro-organismos cresceram efetivamente e foram capazes de oxidar os minérios, independentemente do teor de sulfeto de antimônio contido nas amostras. No entanto, observou-se melhores resultados de lixiviação de Sb $(86,2 \% ; 81,3 \%$ e $78,2 \%)$ para as amostras contendo baixo teor de sulfeto de antimônio ( $2,89 \% ; 6,91 \%$ e 0,84\%, respectivamente). Além disso, os autores concluíram que quanto menor o teor de sulfetos de ferro e arsênico, maior a lixiviação de antimônio.

É importante ressaltar que, embora a bio-oxidação de minérios contendo Sb seja documentada na literatura, ainda se verifica um volume reduzido de estudos, principalmente utilizando micro-organismos termófilos. Nesse contexto, - presente trabalho visa estudar a bio-oxidação de um concentrado sulfetado contendo ferro, antimônio e arsênio pela bactéria termófila moderada S.thermosulfidooxidans, a fim de avaliar o efeito da concentração inicial de sulfato ferroso e do $\mathrm{pH}$ sobre a bio-oxidação, sobretudo no comportamento do antimônio, bem como de seu sulfeto durante o processo de oxidação microbiana.

\section{MATERIAIS E MÉTODOS}

Os experimentos de bio-oxidação foram realizados com uma amostra de concentrado de flotação com tamanho de partícula $100 \%$ inferior a $0,037 \mathrm{~mm}$. A caracterização mineralógica obtida por difração de raios- $X(D R X)$, identificou a presença de muscovita $\left(\mathrm{KAl}_{2} \mathrm{Si}_{3} \mathrm{AlO}_{10}(\mathrm{OH}, \mathrm{F})_{2}\right)$, clorita $\left.(\mathrm{Mg}, \mathrm{Al}, \mathrm{Fe})_{12}(\mathrm{Si}, \mathrm{Al})_{8} \mathrm{O}_{20}(\mathrm{OH})_{16}\right)$, quartzo $\left(\mathrm{SiO}_{2}\right)$, arsenopirita (FeAsS), pirita $\left(\mathrm{FeS}_{2}\right)$, estibinita $\left(\mathrm{Sb}_{2} \mathrm{~S}_{3}\right)$ e gudmundita (FeSbS) na amostra. As análises de DRX foram conduzidas em amostras na forma de pó usando um difratômetro convencional (PanAnalytical, modelo Empirean), com radiação $\mathrm{CuK} \alpha$, intervalo angular (20): 8-80. A interpretação dos difratogramas foi realizada através de comparações com os padrões do banco de dados (JCPDS) com a utilização do software "X'Pert HighScore", versão I.0.

De acordo com a análise química via ICP-OES (Varian 725-ES), os teores dos elementos principais foram: $\mathrm{Fe}(10,58 \pm 0,16 \%)$, As (I,88 $\pm 0,04 \%)$, Sb $(3,16 \pm 0,65 \%)$. $\mathrm{O}$ teor de enxofre total, (assumido como sulfeto) foi igual

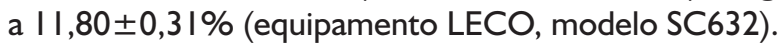

Nos ensaios foi utilizada uma cepa de Sulfobacillus thermosulfidooxidans (DSMZ 9293), cultivada em meio Norris $\left(0,04 \mathrm{~g} \mathrm{~L}^{-1}\right.$ de $\left(\mathrm{NH}_{4}\right)_{2} \mathrm{SO}_{4}, 0,04 \mathrm{~g} \mathrm{~L}^{-1}$ de $\mathrm{K}_{2} \mathrm{HPO}_{4} \mathrm{e}$ $0,08 \mathrm{~g} \mathrm{~L}^{-1}$ de $\mathrm{MgSO}_{4} .7 \mathrm{H}_{2} \mathrm{O}$ ) suplementado com 0 , I $\mathrm{g} \mathrm{L}^{-1} \mathrm{de}$ 
extrato de levedura. Como substrato, foi utilizado $2,5 \mathrm{~g} \mathrm{~L}^{-1}$ de $\mathrm{Fe}^{2+}\left(\mathrm{FeSO}_{4} \cdot 7 \mathrm{H}_{2} \mathrm{O}\right)$.

Os experimentos de bio-oxidação foram conduzidos em frascos Erlenmeyer com capacidade de $250 \mathrm{~mL}$, sendo $150 \mathrm{~mL}$ o volume total da solução.

A fase aquosa continha meio de cultura Norris, $0, \mathrm{I} \mathrm{g} \mathrm{L}^{-1}$ de extrato de levedura e sulfato ferroso na concentração pré-determinada. Um volume de $300 \mathrm{~mL}$ do inóculo foi filtrado em membranas de celulose (Millipore - 0,22 $\mu \mathrm{m}$ ), sendo transferido para o frasco, gerando uma população bacteriana inicial de $10^{7}$ células $\mathrm{mL}^{-1}$. Os frascos foram incubados em uma mesa agitadora (New Brunswick Scientific, modelo Innova 44) a $47^{\circ} \mathrm{Ce} 150 \mathrm{~min}^{-1}$ em todos os ensaios. Os experimentos foram conduzidos em duplicata, assim como também foi realizado um controle negativo para cada um dos ensaios bióticos, utilizando-se timol como bactericida $(2 \% \mathrm{~m} / \mathrm{v})$. O potencial de oxirredução e o $\mathrm{pH}$ da suspensão foram monitorados diariamente. $\mathrm{O}$ pH da suspensão foi ajustado, quando necessário, pela adição de $\mathrm{I}, 0 \mathrm{~mol} \mathrm{~L}^{-1}$ de $\mathrm{H}_{2} \mathrm{SO}_{4}$ ou solução $5,0 \mathrm{~mol} \mathrm{~L}^{-1}$ de $\mathrm{NaOH}$. Para a medição do $\mathrm{pH}$ foi utilizado um pHmetro (Digimed DM-22), composto de eletrodo de membrana de vidro. O potencial de oxirredução foi medido periodicamente através de um eletrodo de $\mathrm{Ag} / \mathrm{AgCl}$ em um Ehmetro-Digimed DM-20. As perdas por evaporação durante a bio-oxidação foram repostas pela adição de água destilada até o peso inicial. O número de células vivas foi monitorada utilizando um microscópio óptico (Leica-DM 2500M) com o auxílio de uma câmara de Neubauer.

Foram realizadas, periodicamente, análises químicas das concentrações de ferro arsênio e antimônio da solução via ICP-OES (725/ES-Varian $\left.{ }^{\circledR}\right)$. O acompanhamento do nível de oxidação do concentrado, em termos de lixiviação, foi feito através da evolução da solubilização de arsênio com o tempo, uma vez que houve adição externa de $\mathrm{Fe} e \mathrm{~S}$ na forma de $\mathrm{FeSO}_{4} \cdot 7 \mathrm{H}_{2} \mathrm{O}_{\text {e }} \mathrm{H}_{2} \mathrm{SO}_{4}$ (utilizado para ajuste do $\mathrm{pH}$ ) e nos sais constituintes do meio de cultura Norris. Ao final dos experimentos, os produtos sólidos foram filtrados, lavados com água destilada, secos, pesados e analisados através da técnica de difração de raio $X$ (DRX) num equipamento PanAnalytical (modelo Empirean) e MEV/EDS (Tescan, modelo Vega 3). A preparação das amostras para observação no MEV/EDS envolveu o embutimento do sólido em resina epóxi e, após seu endurecimento, planificação da superfície por meio de lixamento e, finalmente, polimento para obtenção de uma superfície lisa. Após a preparação das amostras, estas foram revestidas com carbono então analisadas.

\section{RESULTADOS E DISCUSSÃO}

\section{I Efeito da Concentração Inicial de Íons $\mathrm{Fe}^{2+}$.}

Foram realizados ensaios para verificar o efeito da concentração inicial de $\mathrm{Fe}^{2+}$, substrato para crescimento bacteriano, sobre a bio-oxidação do concentrado sulfetado. Nesses ensaios, as condições utilizadas foram: $47^{\circ} \mathrm{C}, \mathrm{pH}$ I ,8, percentual de sólido igual a $I, 5 \%$ e diferentes concentrações inicial de $\mathrm{Fe}^{2+}\left(0,0 \mathrm{~g} \mathrm{~L}^{-1}, 2,5 \mathrm{~g} \mathrm{~L}^{-1}, 5,0 \mathrm{~g} \mathrm{~L}^{-1}\right.$ e $\left.10 \mathrm{~g} \mathrm{~L}^{-1}\right)$. Os valores de Eh obtidos utilizando-se diferentes concentrações iniciais de íons $\mathrm{Fe}^{2+}$ são apresentados na Tabela I. Os valores de Eh em todas as condições bióticas testadas foram superiores $\left(550-600 \mathrm{mV}\right.$, no $\left.3^{\circ} \mathrm{dia}\right)$ aos apresentados nos ensaios conduzidos sem inoculação $(\approx 380 \mathrm{mV}$ ao final do ensaio). Desta forma, comprova-se $\circ$ efeito catalisador dos sistemas biológicos na velocidade de oxidação do íon ferroso. Os resultados de Eh obtidos na presença de microorganismos $(600 \mathrm{mV})$ encontram-se próximos ao descrito na literatura para experimentos conduzidos com a espécie S.thermosulfidooxidans, a $50^{\circ} \mathrm{C}(650-700 \mathrm{mV})$ [7].

$\mathrm{O}$ crescimento bacteriano (Tabela I) apresentou comportamento similar em todas as concentrações iniciais de $\mathrm{Fe}^{2+}$ testadas. Tal fato evidencia que o concentrado sulfetado fornece este substrato em quantidade suficiente para o crescimento microbiano, conforme mostra a Figura la para o ensaio sem adição de $\mathrm{Fe}^{2+}\left(498,0 \mathrm{mg} \mathrm{L}^{-1}\right.$ de ferro total, no $2^{\circ}$ dia de ensaio).

Por outro lado, foi constatada a influência positiva da suplementação de ferro na lixiviação de As, sendo sugerida a necessidade de suplementação deste substrato para melhor oxidação do concentrado sulfetado (Figura Ib). A extração final de arsênio atingiu $16,0 \%, 25,4 \%, 36,6 \%$ e $46,8 \%$ para as concentrações iniciais de $\mathrm{Fe}^{2+}$ de $0 \mathrm{~g} \mathrm{~L}^{-1}, 2,5 \mathrm{~g} \mathrm{~L}^{-1}$, $5,0 \mathrm{~g} \mathrm{~L}^{-1}$ e $10,0 \mathrm{~g} \mathrm{~L}^{-1}$, respectivamente. A influência positiva da suplementação com $\mathrm{Fe}^{2+}$ na lixiviação de metais também foi observada durante a bio-oxidação de arsenopirita [10]. Segundo Tuoven et al [10], a suplementação com 6,7 $\mathrm{g} \mathrm{L}^{-1}$ de $\mathrm{Fe}^{2+}$ (na forma de sulfato ferroso) promoveu aumento na concentração de As dissolvido de $599 \mathrm{mg} \mathrm{L}^{-1}$ para $899 \mathrm{mg} \mathrm{L}^{-1}$.

Tabela I. Valores de Eh e número de células vivas (células $\mathrm{mL}^{-1}$ ) nos ensaios de bio-oxidação do concentrado sulfetado por $\mathrm{S}$. thermosulfidooxidans. Condições experimentais: $\mathrm{pH}$ I,80; densidade da polpa: I,5\% $(\mathrm{m} / \mathrm{v})$ e $47^{\circ} \mathrm{C}$

\begin{tabular}{|c|c|c|c|c|c|c|c|}
\hline \multirow{2}{*}{ Parâmetro } & \multicolumn{4}{|c|}{ Efeito da concentração de $\mathrm{Fe}^{2+}\left(\mathrm{g} \mathrm{L}^{-1}\right)$} & \multicolumn{3}{|c|}{ Efeito do pH } \\
\hline & $\mathbf{0}$ & 2.5 & 5 & 10 & 1.5 & 1.75 & 2 \\
\hline Potencial da solução $(\mathrm{mV}) 3^{\circ}$ dia* & 562 & 585 & 577 & 541 & 575 & 559 & 544 \\
\hline Potencial ao final do ensaio $(\mathrm{mV})$ & 618 & 503 & 540 & 538 & 486 & 566 & 524 \\
\hline Valor final de Eh nos ensaios não inoculados (mV) & 392 & 384 & 390 & 409 & 397 & 382 & 369 \\
\hline Número de células no $3^{\circ}$ dia $\left(10^{8}\right.$ células $\left.\mathrm{mL}^{-1}\right)$ & $\mathrm{I}, 28$ & $\mathrm{I}, 88$ & $\mathrm{I}, 38$ & 1,30 & 1,25 & 2,25 & 0,6 \\
\hline Número de células ao final do ensaio $\left(10^{8}\right.$ células $\left.\mathrm{mL}^{-1}\right)$ & 0,67 & 0,32 & 0,50 & 0,40 & 0,10 & 1,93 & 1,05 \\
\hline
\end{tabular}

*Segundo dia nos ensaios, no qual foi estudado o efeito do $\mathrm{pH}$. 


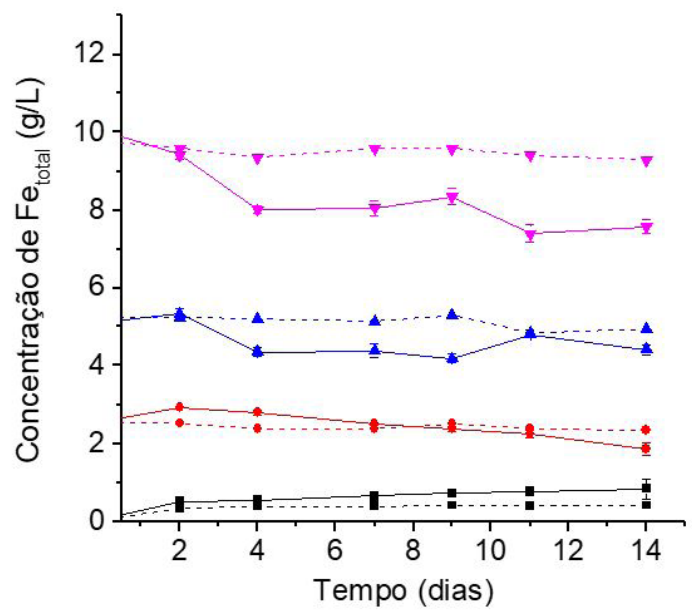

(a)

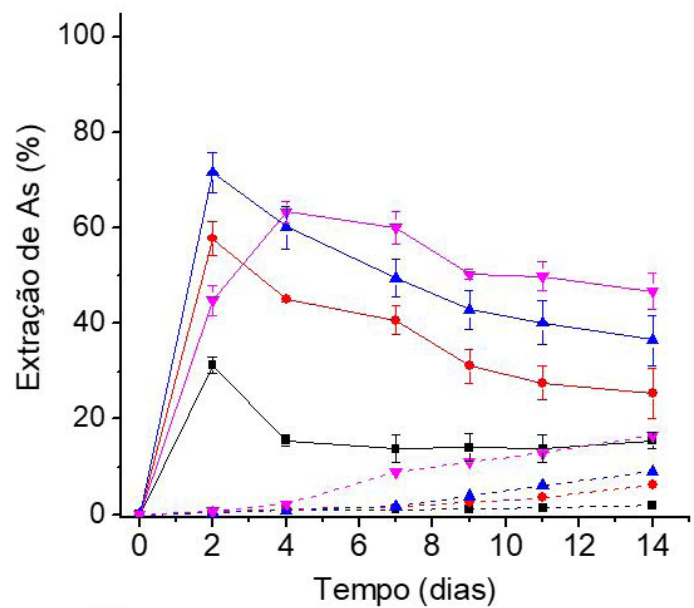

(b)

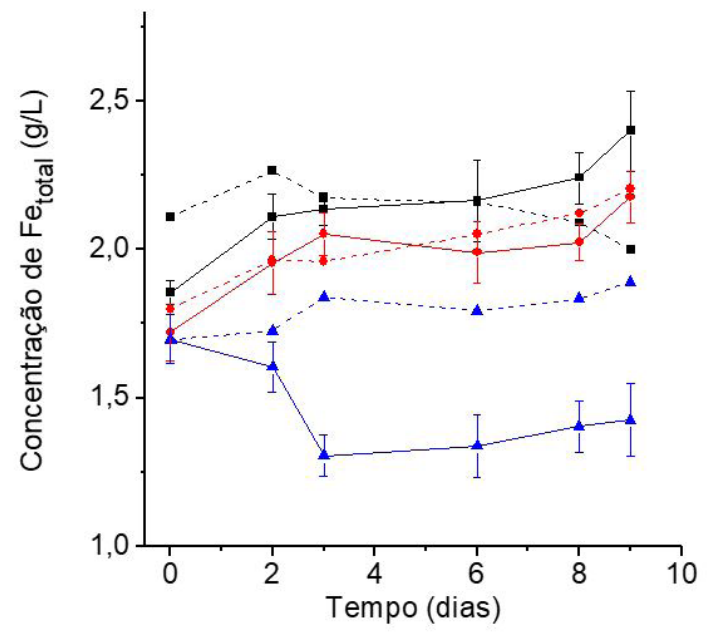

(c)

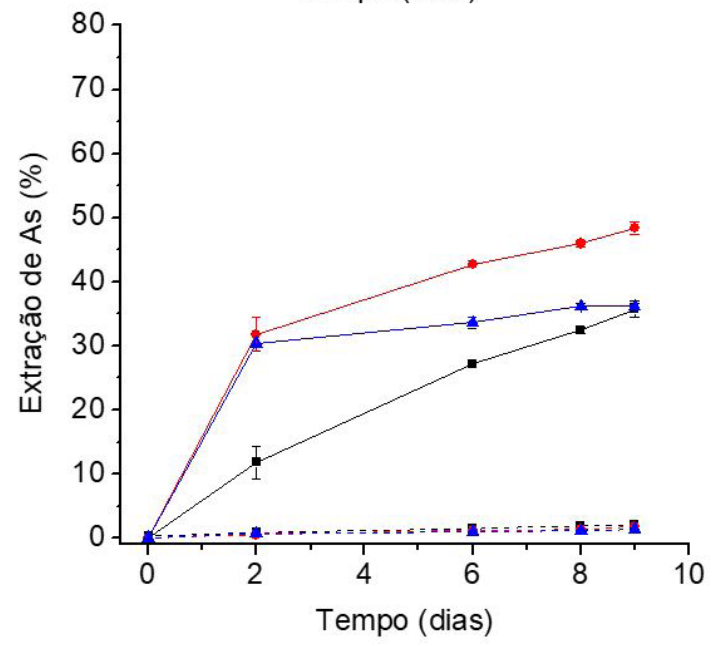

(d)

Figura I. Perfil das concentrações de Fe total (a e c) e extração de arsênio (b e d) no estudo da influência da concentração inicial de Fe ${ }^{2+}$ (a e b) e do $\mathrm{pH}$ (c e d) na bio-oxidação do concentrado sulfetado. Condições experimentais: $\mathrm{pH}$ I,8; temperatura: $47^{\circ} \mathrm{C}$; I,5\% de sólidos ( $\mathrm{m} / \mathrm{v}$ ) e I4 dias de ensaio (Figura la e Ib). I,5\% de sólido; temperatura: $47^{\circ} \mathrm{C}$ e 9 dias de ensaio (Figura I c e Id). As linhas continuas correspondem aos ensaios inoculados e as linhas tracejadas aos respectivos frascos controle. Símbolos: (a e b: quadrado - $0 \mathrm{~g} \mathrm{~L}^{-1}$; círculo - 2,5 $\mathrm{g} \mathrm{L}^{-1}$; triângulo - 5,0 g L-1; triangulo invertido - $\left.10 \mathrm{~g} \mathrm{~L}^{-1}\right)$; (c e d: quadrado - $\mathrm{pH} \mathrm{I,50;} \mathrm{circulo} \mathrm{-} \mathrm{pH} \mathrm{I,75;} \mathrm{triângulo} \mathrm{-} \mathrm{pH}$ 2, I0).

A queda na concentração de ferro total (Figura la) e na extração de arsênio (Figura Ib) para o ensaio com $10 \mathrm{~g} \mathrm{~L}-\mathrm{I}$ de $\mathrm{Fe} 2+$ é resultante da formação de precipitados contendo os elementos, uma vez que os resultados de DRX confirmam a presença de jarosita nos ensaios suplementados com $\mathrm{Fe}^{2+}$ (Figura 2).

Os difratogramas da figura 2 evidenciam também o efeito catalizador da oxidação mediada pelos microorganismos em relação ao sistema não inoculado, no qual ainda são observados vários picos relativos aos sulfetos em 28, $5^{\circ}(\mathrm{P}), 33^{\circ}(\mathrm{P}), 37^{\circ}(\mathrm{P} / \mathrm{A} / \mathrm{E}), 41^{\circ}(\mathrm{P} / \mathrm{A}), 47^{\circ}(\mathrm{P} / \mathrm{E} / \mathrm{G})$ e $56,5^{\circ}$ (P/A). Por outro lado, na amostra bio-oxidação verifica-se apenas os picos de pirita/estibinita/gudmundita $\left(2 \Theta=47^{\circ}\right.$; em vermelho) e arsenopirita/pirita $\left(2 \Theta=56^{\circ}\right.$; em azul). A adição de $10 \mathrm{~g} \mathrm{~L}^{-1}$ de íons $\mathrm{Fe}^{2+}$ ( Figura I a) possibilitou uma melhor oxidação dos sulfetos, permanecendo apenas um pico em $47^{\circ}(\mathrm{P} / \mathrm{E} / \mathrm{G})$.

A evolução da extração de antimônio, utilizando-se diferentes concentrações iniciais de $\mathrm{Fe}^{2+}$ na condição de $\mathrm{pH} \mathrm{I,8,} \mathrm{nos} \mathrm{ensaios} \mathrm{inoculados,} \mathrm{está} \mathrm{apresentada} \mathrm{na} \mathrm{Figura} \mathrm{3a.}$
A oxidação microbiana dos sulfetos contendo antimônio foi caracterizada pela baixa solubilização deste elemento, pois os valores de extração, ao final dos ensaios conduzidos com $0,0 \mathrm{~g} \mathrm{~L}^{-1}, 2,5 \mathrm{~g} \mathrm{~L}^{-1}, 5,0 \mathrm{~g} \mathrm{~L}^{-1}$ e $10,0 \mathrm{~g} \mathrm{~L}^{-1} \mathrm{de} \mathrm{Fe}^{2+}$ foram iguais a $6,0 \%\left(28,00 \mathrm{mg} \mathrm{L}^{-1}\right), 2,3 \%\left(\right.$ (I I,00 $\left.\mathrm{mg} \mathrm{L}^{-1}\right), 0,4 \%\left(\mathrm{I}, 95 \mathrm{mg} \mathrm{L}^{-1}\right)$ e $0,6 \%\left(2,67 \mathrm{mg} \mathrm{L}^{-1}\right)$, respectivamente. Além disto, nos ensaios conduzidos na presença de micro-organismos os valores de extração de antimônio não se sobressaíram em relação aos resultados obtidos nas condições abióticas (dado não mostrado), conforme apresentado em trabalho anterior [II].

Com relação à oxidação de sulfetos de antimônio, ainda não há muitos relatos na literatura sobre as fases formadas durante o processo. Contudo, sabe-se que o Sb liberado apresenta baixa solubilidade, podendo formar precipitados como $(\mathrm{SbO})_{2} \mathrm{SO}_{4}$ e $\left(\mathrm{SbO}_{2}\right)_{2} \mathrm{SO}_{4}[13,14]$.

$\mathrm{O}$ efeito da concentração do ferro na solubilidade do $\mathrm{Sb}$ ainda não foi relatado na literatura em estudos de bio-oxidação de sulfetos contendo o elemento. No entanto, no presente trabalho, pela Figura 3a, observa-se que com o 

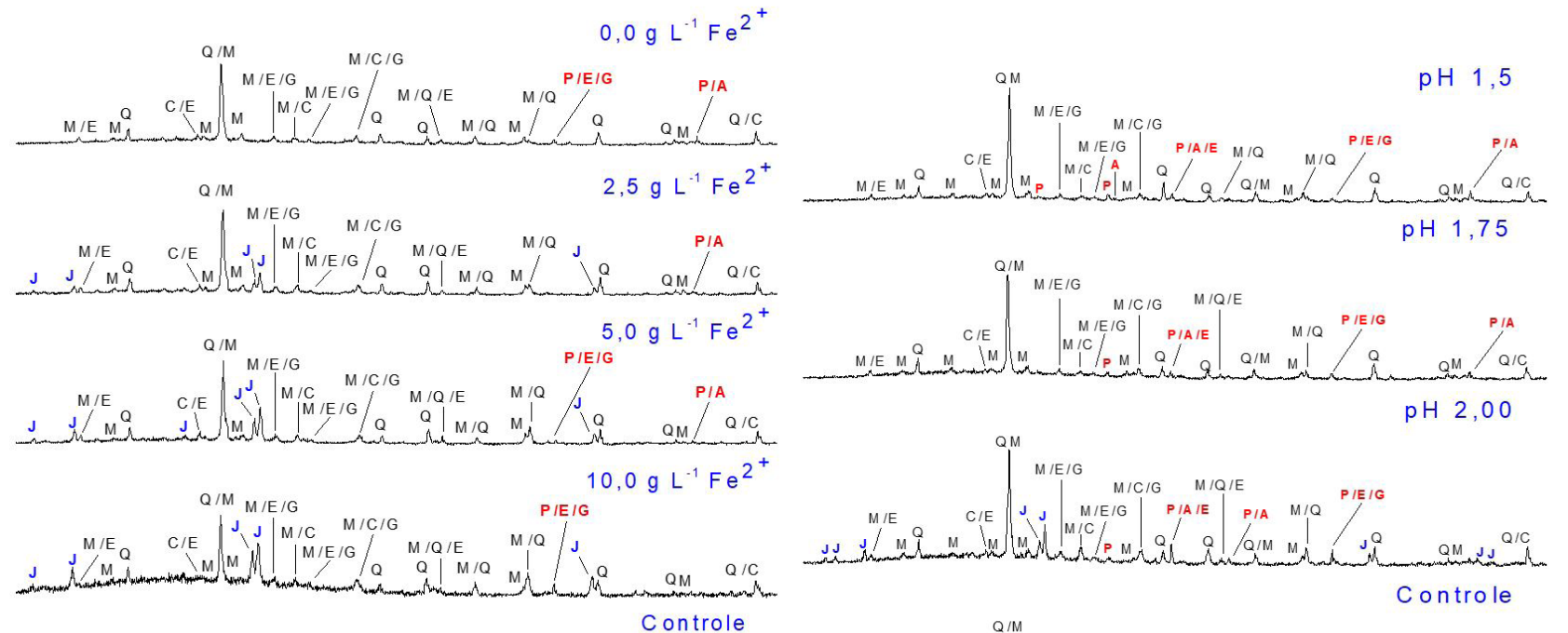

$\mathrm{pH} \mathrm{2,00}$
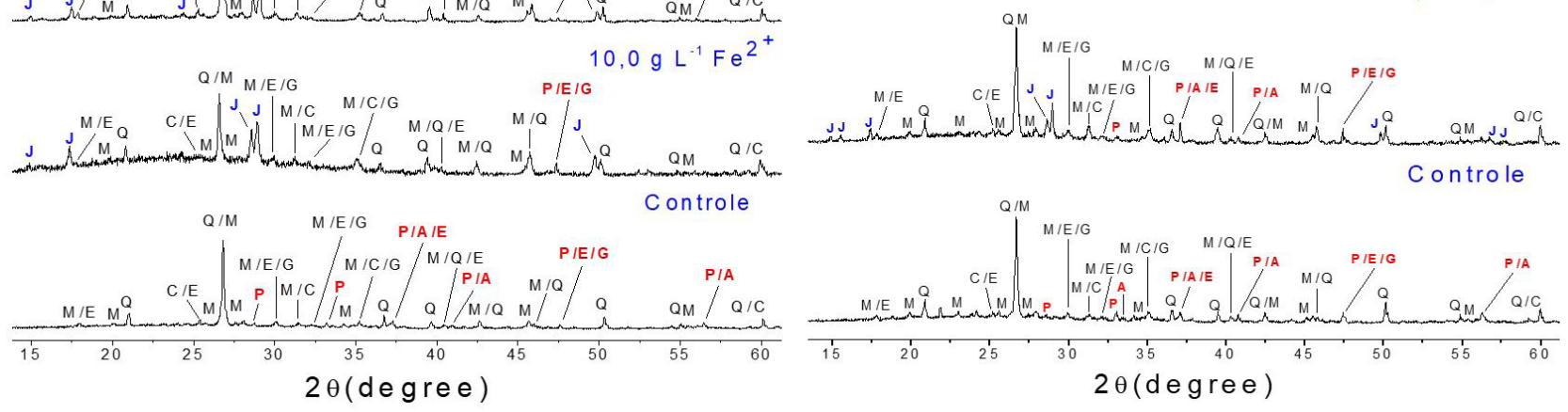

Figura 2. Difração de raios $X(D R X)$ dos produtos gerados no estudo da influência da concentração inicial de (a) $\mathrm{Fe}^{2+}$ e do (b) pH na bio-oxidação do concentrado sulfetado. Condições experimentais: $\mathrm{pH}$ I,8; temperatura: $47^{\circ} \mathrm{C}$; I,5\% de sólidos (m/v) e I4 dias de ensaio (Figura $\left.2 \mathrm{a}\right)$. I,5\% de sólido, temperatura: $47^{\circ} \mathrm{C}$ e 9 dias de ensaio (Figura 2b). Símbolos: M, muscovita; C, clorita; Q, quartzo; P, pirita; A, arsenopirita; E, estibinita; G, gudmundita; J, jarosita.

(a)

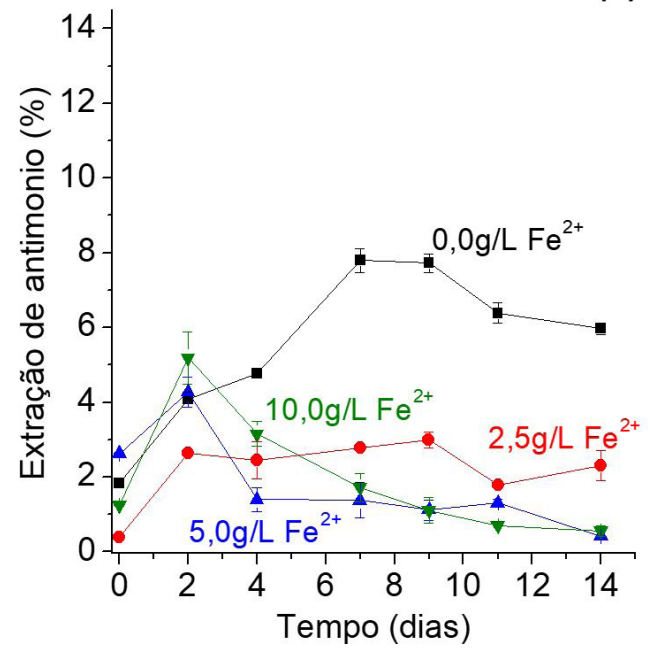

(b)

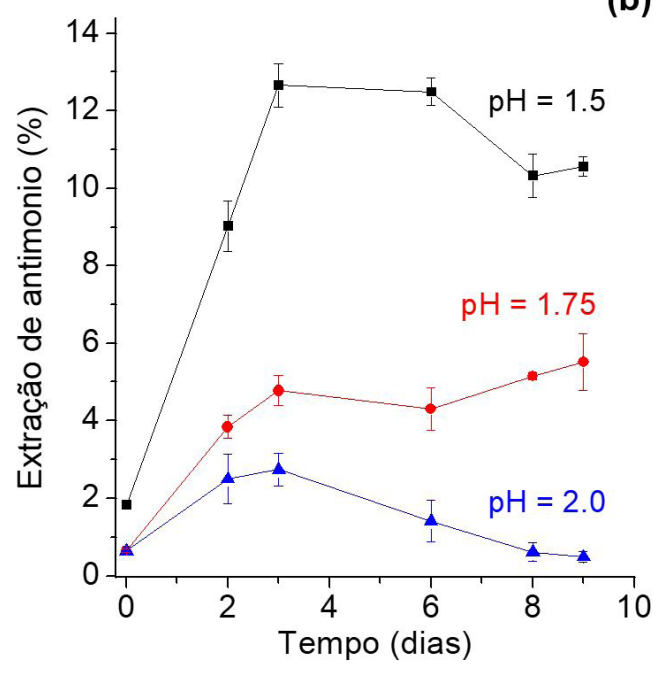

Figura 3. Evolução da extração de antimônio com o tempo nos ensaios de bio-oxidação do concentrado sulfetado em diferentes concentrações de (a) $\mathrm{Fe}^{2+}$ e (b) $\mathrm{pH}$. Condições experimentais: I,5\% de sólidos (m/v); temperatura: $47^{\circ} \mathrm{C}$.

aumento da concentração inicial de íons $\mathrm{Fe}^{2+}$ foi verificada uma redução da solubilização do antimônio. Sugere-se, portanto, que o aumento na concentração de ferro pode ter contribuído para: i) favorecimento da geração de precipitados contendo antimônio pelo sulfato proveniente do sulfato ferroso, gerando óxidos insolúveis (( $\mathrm{SbO})_{2} \mathrm{SO}_{4}$ e $\left.\left(\mathrm{SbO}_{2}\right)_{2} \mathrm{SO}_{4}\right)$; ii) arraste do elemento durante a precipitação de fases secundárias como jarosita; iii) aumento da força iônica, em função do acréscimo na concentração de $\mathrm{Fe}^{2+}$, na formação de precipitados.

Em síntese, foi possível inferir que a suplementação com $\mathrm{Fe}^{2+}$ se faz necessária para uma eficiente oxidação do concentrado sulfetado. Além disso, a melhor condição foi alcançada pelo uso de $10,0 \mathrm{~g} \mathrm{~L}^{-1}$ de íons $\mathrm{Fe}^{2+}$ como mostram as Figura la e 2. 


\subsection{Efeito do $\mathrm{pH}$}

Na Tabela I, são apresentados os resultados do efeito do $\mathrm{pH}$ nos valores de Eh e no número de células vivas durante os ensaios de bio-oxidação. Os valores de Eh em todas as condições bióticas avaliadas foram significativamente superiores $\left(\approx 550 \mathrm{mV}\right.$, no $\left.2^{\circ} \mathrm{dia}\right)$ aos apresentados nos ensaios conduzidos na ausência de micro-organismos $(\approx 370 \mathrm{mV})$. Além disto, em pH I,5, as condições não foram ideias para o crescimento microbiano, pois as contagens bacterianas eram da ordem de $10^{7}$ células $\mathrm{mL}^{-1}$ no último dia de ensaio contra $10^{8}$ células $\mathrm{mL}^{-1}$ nos ensaios conduzidos em $\mathrm{pH}$ I,75 e 2,00 (Tabela I). Esse resultado concerne com o estudo realizado por Karavaiko et al. [10], no qual relata-se que $S$. thermosulfidooxidans apresenta crescimento ótimo na faixa de $\mathrm{pH} \mathrm{I,7-I,8.}$

$\mathrm{Na}$ Figure Ic, é apresentada a variação da concentração de ferro total nos experimentos onde $\mathrm{opH}$ foi variado. As concentrações de ferro nos ensaios inoculados e não inoculados são próximas, com exceção do experimento conduzido em pH 2.0, no qual a concentração do elemento é menor no sistema inoculado. Além disto, o efeito do $\mathrm{pH}$ na extração de arsênio, mostrado na Figura Id, indica inexpressiva dissolução química de arsênio no ensaio controle. Por outro lado, a oxidação biológica apresentou resultados satisfatórios, sendo que as condições de pH I,50; I,75 e 2,00, alcançaram extrações finais iguais a 35,6\%; 48,0\% e 36,2\%, respectivamente.

Nos ensaios conduzidos em pH I,50, a baixa solubilização do arsênio pode ser atribuída à condição menos favorável para o crescimento microbiano, conforme discutido anteriormente (Tabela I). A distinção entre os valores de extração final de arsênio observada nas condições de $\mathrm{pH} \mathrm{I,75} \mathrm{e} \mathrm{2,00} \mathrm{pode} \mathrm{estar}$ relacionada ao efeito do aumento do $\mathrm{pH}$ sobre a redução na solubilidade do elemento, em função da formação de precipitados contendo o metal, tais como arsenato férrico e jarosita contendo arsênio, conforme relatado por Henao e Godoy [5]. A redução abrupta na concentração de ferro total e a presença de picos referente à jarosita em pH 2,0 (Figura Id e Figura 2) corroboram a suposição de que nesta condição de $\mathrm{pH}$ a formação de precipitados férricos é mais acentuada do que em $\mathrm{pH}$ I,75. A influência do $\mathrm{pH}$ na formação de precipitados contendo Fe e As também foi observada por Cassity e Pesic [8] durante a biolixiviação de um minério de arsenopirita.

A evolução da extração de antimônio obtida nos ensaios em diferentes valores de $\mathrm{pH}$ está apresentada na Figura $3 \mathrm{~b}$. Assim como no estudo da influência da concentração de $\mathrm{Fe}^{2+}$, foi constatada a baixa solubilização de antimônio. Os valores de extração do elemento, ao final do experimento, para os ensaios bióticos com pH I,50; I,75 e 2,00 foram iguais a $10,56 \% ; 5,50 \%$ e $0,50 \%$, respectivamente. Os resultados apontam o efeito químico na extração de antimônio, sendo que em condições de $\mathrm{pH}$ mais baixo a extração deste elemento é maior. Além disso, não houve diferença na extração do elemento nos ensaios bióticos e abióticos, conforme apresentado anteriormente [II].

Torma e Gabra [13], em seus estudos sobre biolixiviação de estibinita de elevada pureza $(70,2 \% \mathrm{Sb})$, avaliaram o efeito do $\mathrm{pH}(1,50-3,50)$ sobre a extração de antimônio. Foi constatado que, para valores de $\mathrm{pH}$ maiores do que I,50, há uma redução na concentração de antimônio com o aumento desta variável, fato este que concerne com os resultados obtidos no presente estudo. Ressalta-se que os autores não apresentaram uma discussão crítica sobre a influência do $\mathrm{pH}$ na dissolução de antimônio, como também não há informações suficientes para a compreensão do efeito deste parâmetro no processo de biolixiviação, tais como: evolução do crescimento microbiano, oxidação da matriz mineral e produtos formados.

Em síntese, a solubilização ótima de arsênio foi verificada em pH I,75. Em pH 2,0, a redução na concentração do elemento em solução parece estar associada à formação de precipitados, a exemplo do arsenato férrico e da jarosita. Por outro lado, o processo conduzido em pH I,5 desfavorece o crescimento microbiano, bem como a oxidação do concentrado sulfetado.

A análise de DRX mostrou que em $\mathrm{pH} \mathrm{I} \mathrm{,5} \mathrm{o} \mathrm{processo}$ de bio-oxidação foi menos eficiente, uma vez que foram observados mais picos (localizados em $29^{\circ}(\mathrm{P}), 33^{\circ}(\mathrm{P})$, 33,5 (A), 37 $\left.(\mathrm{P} / \mathrm{A} / \mathrm{E}), 47^{\circ}(\mathrm{P} / \mathrm{E} / \mathrm{G}), 56^{\circ}(\mathrm{P} / \mathrm{A})\right)$ relativos aos sulfetos do que em $\mathrm{pH} \quad \mathrm{I}, 75$ e 2,00 . Já para os ensaios realizados em $\mathrm{pH}$ I,75 e 2,00, a proporção dos picos referentes aos sulfetos foi a mesma em ambos valores de $\mathrm{pH}$, ou seja foram observados picos de sulfetos em $33^{\circ}(\mathrm{P})$, $37^{\circ}$ (P/A/E), $47^{\circ}$ (P/E/G), 56 (P/A).

As análises de MEV/EDS também confirmaram o efeito catalisador do $S$. thermosulfidooxidans na oxidação do concentrado sulfetado em relação à oxidação química. No ensaio abiótico (Figura 4a) realizado com $10 \mathrm{~g} \mathrm{~L}^{-1} \mathrm{de} \mathrm{Fe}^{2+}$, foi constatado que o nível de oxidação foi significativamente baixo, sendo presenciados vários cristais de sulfetos. Porém, na oxidação mediada pelos micro-organismos, a frequência destas fases foi significativamente inferior (Figura 4b). Além disso, neste produto, a presença de fases de pirita e, principalmente, arsenopirita não é recorrente, evidenciado a oxidação destes minerais.

Por outro lado, os sulfetos de antimônio são pouco susceptíveis ao processo de bio-oxidação, uma vez que estes foram identificados com frequência e, na maioria dos casos, com morfologia similar aos encontrados no controle abiótico. Como exemplo, a Figura 5 mostra cristais de gudmundita presentes nos produtos obtidos no ensaio abiótico (Figura 5a) e condição biótica (Figura $5 b$ ), respectivamente.

A formação de óxidos insolúveis ((SbO) $)_{2} \mathrm{SO}_{4}$ e $\left.\left(\mathrm{SbO}_{2}\right)_{2} \mathrm{SO}_{4}\right)$ como consequência da bio-oxidação de sulfetos de antimônio é relatada na literatura $[13,14]$ para justificar a baixa extração de antimônio. Porém, a presença destes precipitados não foi observada no presente estudo. Logo a baixa reatividade dos sulfetos de antimônio justifica os dados mostrados na Figura 3. 

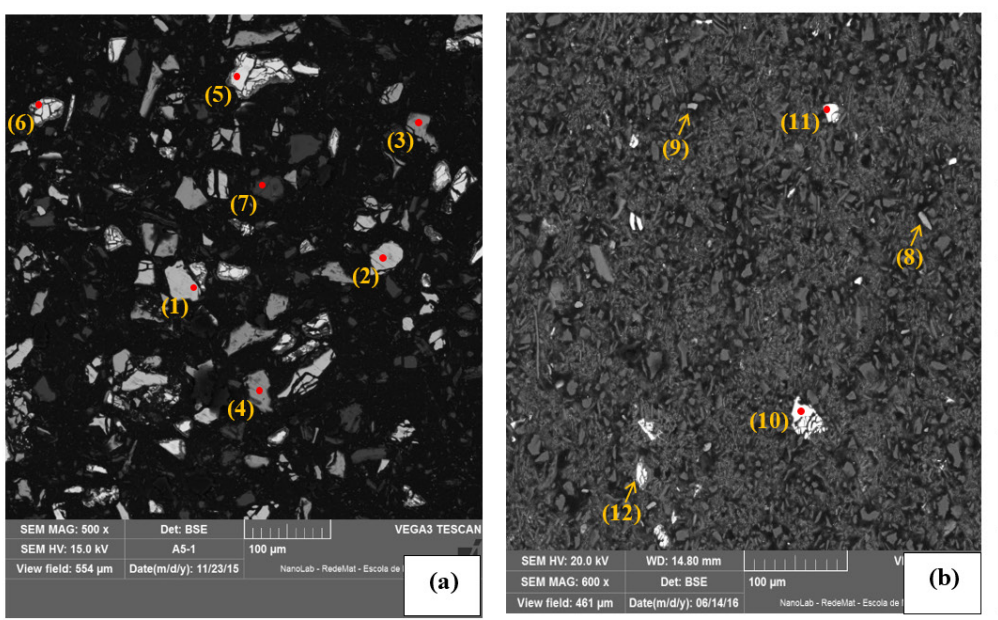

\begin{tabular}{|c|c|c|c|}
\hline \multicolumn{4}{|c|}{$\begin{array}{c}\text { Análise química semi-quantitativa por EDS } \\
\text { (\% - massa) }\end{array}$} \\
\hline Ponto & $\%$ & Ponto & $\%$ \\
\hline \multirow{4}{*}{1} & $42,8 \% \mathrm{As}$ & & $52,2 \mathrm{Si}$ \\
& $34,8 \% \mathrm{Fe}$ & 7 & $45,8 \mathrm{O}$ \\
& $22,4 \% \mathrm{~S}$ & & \\
\hline \multirow{4}{*}{2} & $46,2 \% \mathrm{As}$ & & $39,2 \% \mathrm{Fe}$ \\
& $33,8 \% \mathrm{Fe}$ & 8 & $43,2 \% \mathrm{~S}$ \\
& $20,0 \% \mathrm{~S}$ & & $10,7 \% \mathrm{O}$ \\
\hline \multirow{4}{*}{3} & $48,7 \% \mathrm{Fe}$ & & $37,5 \% \mathrm{Fe}$ \\
& $51,3 \% \mathrm{~S}$ & 9 & $42,6 \% \mathrm{~S}$ \\
& & & $14,9 \% \mathrm{O}$ \\
\hline \multirow{4}{*}{4} & $46,6 \% \mathrm{Fe}$ & & $50,0 \% \mathrm{Sb}$ \\
& $53,4 \% \mathrm{~S}$ & 10 & $27,9 \% \mathrm{~S}$ \\
& & & $13,0 \% \mathrm{Fe}$ \\
& & & $6,2 \% \mathrm{O}$ \\
\hline \multirow{5}{*}{5} & $57,9 \% \mathrm{Sb}$ & & $50,4 \% \mathrm{Sb}$ \\
& $29,2 \% \mathrm{~S}$ & 11 & $24,3 \% \mathrm{~S}$ \\
& $12,9 \% \mathrm{Fe}$ & & $13,2 \% \mathrm{Fe}$ \\
& & & $10,1 \% \mathrm{O}$ \\
\hline \multirow{3}{*}{6} & $58,0 \% \mathrm{Sb}$ & & $57,7 \% \mathrm{Sb}$ \\
& $29,4 \% \mathrm{~S}$ & 12 & $24,3 \% \mathrm{~S}$ \\
& $12,7 \% \mathrm{Fe}$ & & $10,9 \% \mathrm{O}$ \\
\hline
\end{tabular}

Figura 4. Imagens do produto de bio-oxidação obtido no ensaio com adição de $10 \mathrm{~g} \mathrm{~L}^{-1} \mathrm{Fe}^{2+}$. Ensaio: (a) abiótico e (b) biótico.

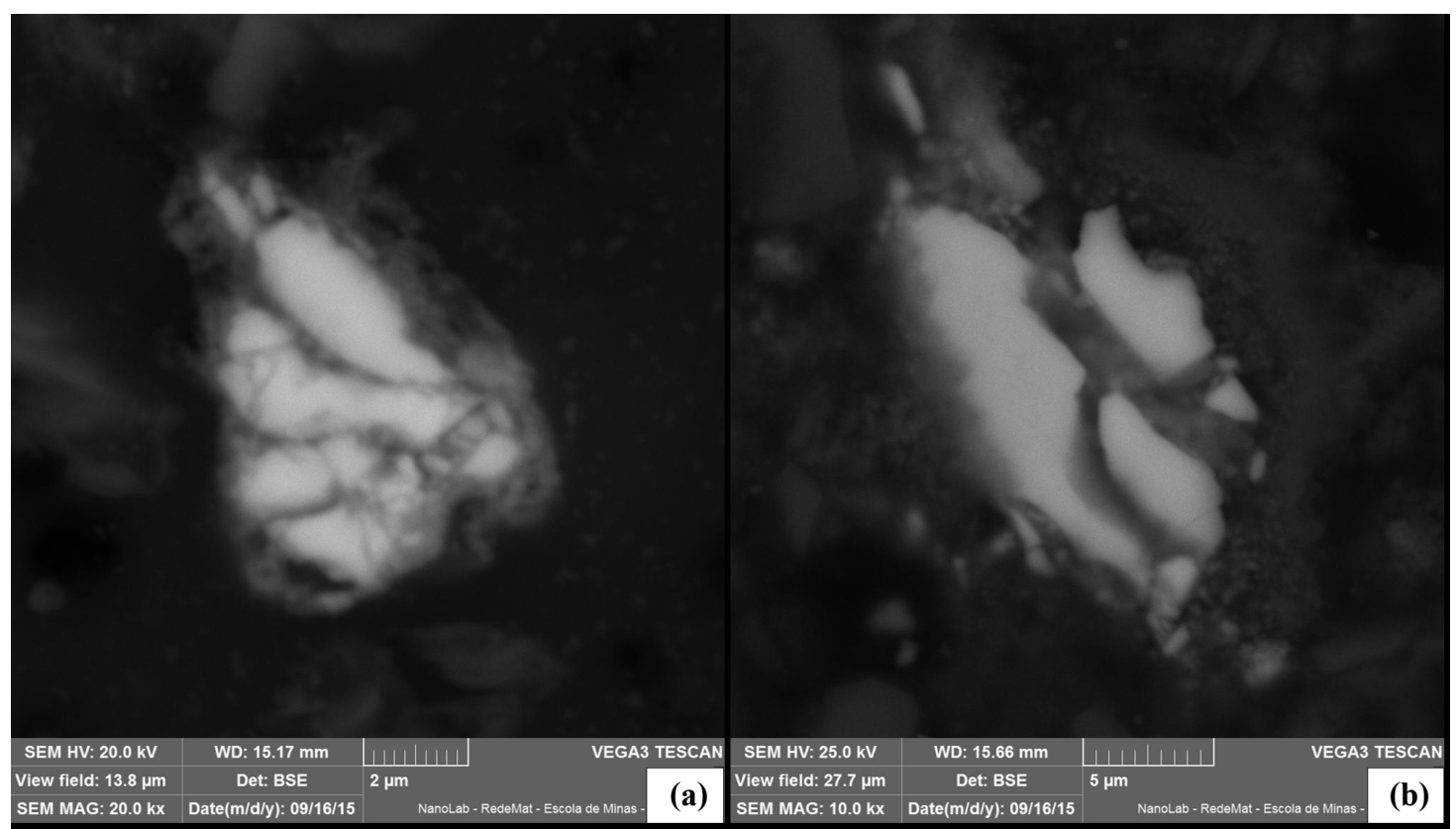

Figura 5. Cristais de gundmudita detectados nos produtos de bio-oxidação do ensaio realizado com I0gL-1 de Fe ${ }^{2+}$. Ensaios (a) abiótico e (b) biótico.

\section{CONCLUSÕES}

O efeito catalisador da espécie $S$. thermosulfidooxidans na oxidação do concentrado sulfetado foi demonstrado, tanto pela significativa dissolução de arsênio, como também pelas análises dos produtos da bio-oxidação. Com base nos resultados, é necessária a adição de íons $\mathrm{Fe}^{2+}$ para se obter elevados rendimentos de oxidação, sendo que $\circ$ uso de $10 \mathrm{~g} \mathrm{~L}^{-1}$ promoveu um aumento de três vezes na extração de arsênio em relação à condição sem a adição externa de ferro. $\mathrm{O}$ pH também tem influência importante e o valor ótimo é I,75-I,80.

O processo de bio-oxidação foi caracterizado pela precipitação de ferro, arsênio, antimônio e enxofre. $O$ arsênio mostrou-se mais estável em solução, sendo possível observar nitidamente a influência da concentração de sulfato ferroso e do $\mathrm{pH}$ na oxidação da amostra. $\mathrm{O}$ antimônio apresentou baixa solubilidade no sistema durante todo o período da bio-oxidação, não havendo diferença significativa entre os ensaios bióticos e os controles químicos, sendo que o aumento da concentração de ferro e do $\mathrm{pH}$ diminuiu a solubilidade do mesmo nos sistemas. Desta forma, processos de biolixiviação não são recomendados para a extração deste elemento.

\section{Agradecimentos}

Os autores agradecem à CAPES, CNPq, Finep eFAPEMIG o apoio financeiro. 


\section{REFERÊNCIAS}

I Kaksonen AH, Mudunuru BM, Hackl R. The role of microorganisms in gold processing and recovery - a review. Hydrometallurgy. 20।4; I42:70-83.

2 Rodrigues MLM, Lopes KCS, Leôncio HC, Silva LAM, Leão VA. Bioleaching of fluoride-bearing secondary copper sulphides: Column experiments with Acidithiobacillus ferrooxidans. Chemical Engineering Journal. 2016;284:12791286.

3 Bevilaqua D, Leite ALLC, Garcia O, Tuovinen OH. Oxidation of chalcopyrite by Acidithiobacillus ferrooxidans and Acidithiobacillus thiooxidans in shake flasks. Process Biochemistry (Barking, London, England). 2002;38(4):587-592.

4 Grigor'eva NV, Tsaplina IA, Panyushkina AE, Kondrat'eva TF. Optimization of bioleaching and oxidation of goldbearing pyrite-arsnopyrite ore concentrate in batch mode. Microbiology. 20I4;83(5):550-557.

5 Henao DMO, Godoy MAM. Jarosite pseudomorph formation from arsenopyrite oxidation using Acidithiobacillus ferrooxidans. Hydrometallurgy. 2010;104(2): 162-168.

6 Oliveira SMB, Blot A, Liguoriimbernon RA, Magat P. Jarosita e plumbojarosita nos gossans do distrito mineiro de Canoas (PR). Revista Brasileira de Geociencias. 1996;26(I):3-12.

7 Scott KM. Solid solution in, and classification of, gossan-derived members of the alunite-jarosite family, northwest Queensland, Australia. The American Mineralogist. 1987;72(I-2): I78-I87.

8 Cassity WD, Pesic B. Interactions of Thiobacillusferrooxidans with arsenite, arsenate and arsenopyrite William. In: Amils R, Ballester A, editors. Biohydrometallurgy and the Environment toward the Mining of the 2Ist Century, Part I. Amsterdam: Elsevier; 1999. p. 52I-532.

9 Márquez M, Gaspar J, Bessler KE, Magela G. Process mineralogy of bacterial oxidized gold ore in São Bento Mine (Brasil). Hydrometallurgy. 2006;83(I-4): I I4-I 23.

I0 Karavaiko, G. I.; Dubinina, G. A.; Kodrateva, T. F. Lithotrophic microorganisms of the oxidative cycles of sulfur and iron. Microbiology, v. 75, n. 5, p. 5I2545, 2006.

I I Silva SR. Bio-oxidação de sulfetos de arsênio e antimônio por Sulfobacillus thermosufidooxidans. Ouro Preto: Universidade Federal de Ouro Preto; 2016.

12 Filella M, Williams PA, Belzile N. Antimony in the environment: knowns and unknowns. Environmental Chemistry. 2009;6(2):95-105.

13 Torma AE, Gabra GG. Oxidation of stibnite by Thiobacillus ferrooxidans. Antonie van Leeuwenhoek. 1977;43(I):I-6.

14 Luptákova A, Macingová E, Ubaldini S, Jencárová J. Bioleaching of antimony minerals by bacteria Acidithiobacillus ferrooxidans and Desulfovibrio desulfuricans. Environ Chem \&Technology. 2008; 102:409-4II.

15 Tsaplina IA, Sorokin V, Zhuravleva AE, Melamud VS, Bogdanova TI, Kondrat'eva TF. Oxidation of gold-antimony ores by a thermoacidophilic microbial consortium. Microbiology. 2013;82(6):680-689.

Recebido em: 25 Dez. 2018

Aceito em: 22 Nov. 2019 
Bio-oxidação de concentrado refratário de ouro por Sulfobacillus Thermosufidooxidans com foco no comportamento do antimônio

\section{NOTAÇÃO}

M: muscovita

C: clorita

Q: quartzo

P: pirita

A: arsenopirita

E: estibinita

G: gudmundita

J: jarosita 